\title{
Convolvulaceae endémicas del Perú
}

\section{Blanca León ${ }^{1,2}$}

${ }^{1}$ Museo de Historia Natural, Av. Arenales 1256, Aptdo. 14-0434, Lima 14, Perú

2 Plant Resources Center, University of Texas at Austin, Austin TX 78712 EE.UU.

blanca.leon@mail.utexas.edu

\section{Resumen}

La familia Convolvulaceae es reconocida en el Perú por presentar 17 géneros y 132 especies (Brako \& Zarucchi, 1993; Ulloa Ulloa et al., 2004), mayormente bejucos y lianas. En este trabajo reconocemos nueve especies y una subespecie como endemismos peruanos en cuatro géneros. Los taxones endémicos ocupan principalmente las regiones Matorral Desértico, Bosques Secos y Desierto Cálido Tropical, entre los 100 y 2000 $\mathrm{m}$ de altitud. Ninguna de estas especies se encuentra representada en el Sistema $\mathrm{Na}-$ cional de Áreas Naturales Protegidas por el Estado.

Palabras claves: Convolvulaceae, Perú, endemismo, plantas endémicas.

\section{Abstract}

The Convolvulaceae are represented in Peru by 17 genera and 132 species (Brako \& Zarucchi, 1993; Ulloa Ulloa et al., 2004), mostly vines and lianas. Here we recognize as endemics nine species and one subspecies in four genera. Endemic taxa are found in Desert Shrubland, Dry Forests and Tropical Costal Desert regions, between 100 and $2000 \mathrm{~m}$ elevation. None of the species have been collected to date within Peru's protected area system.

Keywords: Convolvulaceae, Peru, endemism, endemic plants.

\section{Evolvulus magnus Helwig}

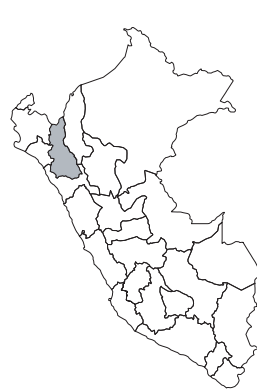

DD

Publicación: Notizbl. Bot. Gart. BerlinDahlem 10(91): 105. 1927.

Colección tipo: A. Weberbauer 4125

Herbarios: B, G-DC; USM!.

Nombre común: Desconocido.

Registro departamental: CA.

Regiones Ecológicas: MDE; 1300—2000 $\mathrm{m}$

SINANPE: Sin registro.

Herbarios peruanos: USM (isotipo).

Observaciones: Subarbusto, descrito de una planta recolectada en 1904. Es conocido, al parecer, sólo de la cuenca del Chancay, en la vertiente del Pacífico, donde crecía entre matorrales abiertos. Hensold (1999) menciona la necesidad de una revisión taxonómica del grupo de esta especie.

\section{Evolvulus piurensis Ooststr.}

\section{CR, B1a}

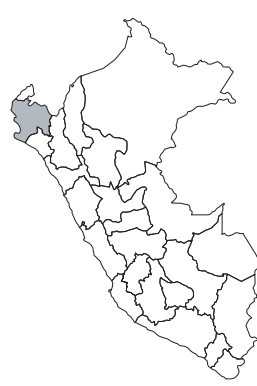

Publicación: Meded. Bot. Mus. Herb. Rijks Univ. Utrecht 14: 82. 1934.

Colección tipo: O. Haught 78

Herbarios: S, US.

Nombre común: Desconocido.

Registro departamental: PI.

Regiones Ecológicas: DCT; altitud desconocida.

SINANPE: Sin registro.

Herbarios peruanos: Ninguno.

Observaciones: Hierba conocida de la costa norte del país. Esta especie fue recolectada en la cuenca del Pariñas, una zona escasamente herborizada.

\section{Evolvulus weberbaueri Helwig}

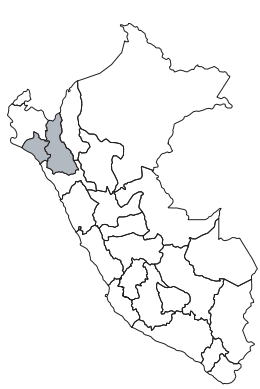

EN, B1a

Publicación: Notizbl. Bot. Gart. BerlinDahlem 10(91): 104. 1927.

Colección tipo: A. Weberbauer 6237

Herbarios: B, NY.

Nombre común: Desconocido.

Registro departamental: CA, LA.

Regiones Ecológicas: BS; 1000—2000 m.

SINANPE: Sin registro.

Herbarios peruanos: USM (1).

Observaciones: Subarbusto conocido de unas pocas localidades en el norte del país. El ejemplar tipo fue recolectado en 1912, entre las cuencas del Tabaconas y Marañón, una zona escasamente herborizada.

\section{Ipomoea pulcherrima Ooststr.}

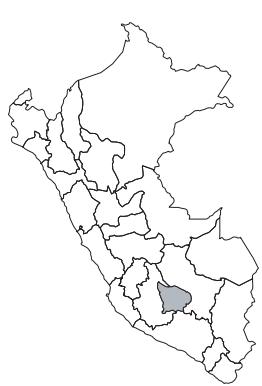

\section{CR, B1ab(iii)}

Publicación: Recueil Trav. Bot. Neerl. 30: 206. 1933.

Colección tipo: A. Weberbauer 5875

Herbarios: B, GH, US.

Nombre común: Desconocido.

Registro departamental: AP.

Regiones Ecológicas: BS; $1100 \mathrm{~m}$.

SINANPE: Sin registro.

Herbarios peruanos: Ninguno.

Observaciones: Arbusto conocido sólo de una localidad entre las cuencas del Pachachaca y del Pampas, donde fue recolectado en fragmentos de bosque seco. Aparentemente, no ha vuelto a ser recolectada desde 1911. 


\section{Ipomoea sawyeri D.F. Austin}

\section{DD}

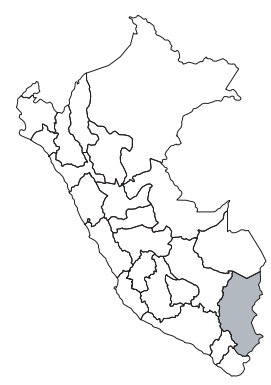

Publicación: Brittonia 43(2): 93-95, f. 1. 1991.

Colección tipo: F. de la Puente 3271

Herbarios: FAU, US.

Nombre común: Desconocido.

Registro departamental: PU.

Regiones Ecológicas: BMHM; $2000 \mathrm{~m}$.

SINANPE: Sin registro.

Herbarios peruanos: Ninguno.

Observaciones: Hierba anual o bejuco, descrito de una planta recolectada en la cuenca del San Gabán. No se conoce detalles del hábitat de esta especie, recolectada en una expedición del Centro Internacional de la Papa (CIP).

\section{Ipomoea wolcottiana Rose subsp. calodendron}

(O’Donell) McPherson

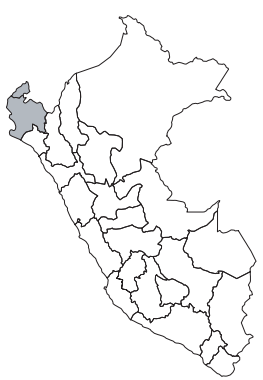

\section{EN, B1a}

Publicación: Ann. Missouri Bot. Gard. 68(4): 544. 1981.

Colección tipo: A. Weberbauer 6396

Herbarios: F, NY, US.

Nombre común: Desconocido.

Registro departamental: PI, TU.

Regiones Ecológicas: DCT; $100-800 \mathrm{~m}$. SINANPE: Sin registro.

Herbarios peruanos: Ninguno.

Observaciones: Árbol de hasta $10 \mathrm{~m}$ de alto, descrito de una planta recolectada en 1912 de la cuenca del río Quiróz, en el noroccidente del país. Otras poblaciones de este taxón son conocidas de localidades dispersas en Piura y Tumbes.

\section{Jacquemontia caudata Helwig}

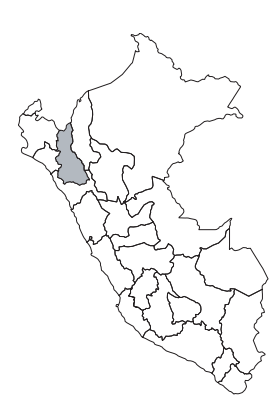

\section{DD}

Publicación: Notizbl. Bot. Gart. BerlinDahlem 9: 1137. 1927.

Colección tipo: A. Weberbauer s.n. Herbarios: B.

Nombre común: Desconocido.

Registro departamental: CA.

Regiones Ecológicas: MDE; $1600 \mathrm{~m}$.

SINANPE: Sin registro.

Herbarios peruanos: Ninguno.

Observaciones: Bejuco descrito de una planta recolectada en la cuenca del Llaucán, un tributario del Marañón. La localidad original está ubicada en una zona con estacionalidad de lluvias marcada y la presencia de una vegetación entre bosque mésico y matorrales semixéricos. Hensold (1999) comentó sobre la incertidumbre taxonómica de esta especie.

\section{Jacquemontia peruviana Helwig}

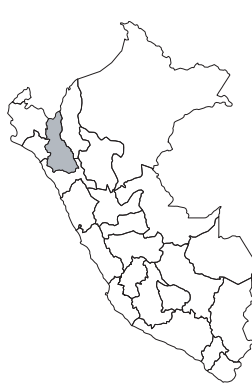

DD

Publicación: Notizbl. Bot. Gart. BerlinDahlem 9: 1138. 1927.

Colección tipo: A. Weberbauer 7139

Herbarios: B.

Nombre común: Desconocido.

Registro departamental: CA.

Regiones Ecológicas: MDE; $1300 \mathrm{~m}$.

SINANPE: Sin registro.

Herbarios peruanos: Ninguno.

Observaciones: Bejuco conocido de la colección tipo, una planta recolectada en 1915, en la cuenca del Marañón. Hensold (1999) comentó sobre la incertidumbre taxonómica de esta especie.

\section{Merremia grandiflora Ooststr.}

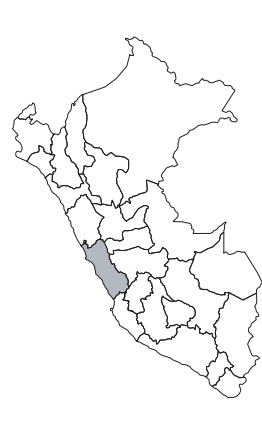

$$
\text { VU, B1a }
$$

Publicación: Recueil Trav. Bot. Neerl. 30: 203. 1933.

Colección tipo: A. Weberbauer 5218

Herbarios: B, F.

Nombre común: Desconocido.

Registro departamental: LI.

Regiones Ecológicas: MDE; 1300—2200 m.

SINANPE: Sin registro.

Herbarios peruanos: USM (3).

Observaciones: Subarbusto conocido, aparentemente sólo de la cuenca del Rímac. El ejemplar tipo fue recolectado en 1909 y existen varias otras colecciones en años posteriores.

\section{Merremia weberbaueri Ooststr.}

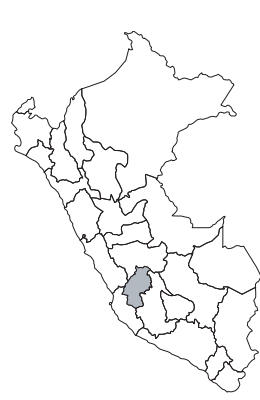

\section{EN, B1a}

Publicación: Recueil Trav. Bot. Neerl. 30: 200. 1933.

Colección tipo: A. Weberbauer 6473

Herbarios: B, U; MOL!

Nombre común: Desconocido.

Registro departamental: HV.

Regiones Ecológicas: MA; $2200 \mathrm{~m}$.

SINANPE: Sin registro.

Herbarios peruanos: MOL (isotipo).

Observaciones: Bejuco conocido de la colección tipo, una planta recolectada en 1912, de la cuenca del Mantaro. Esa parte del país requiere de mayor herborización y su conservación debería ser de interés a botánicos y conservacionistas. 